\title{
Knowledge, Attitude, and Prevention Practice of Cosmetology Students toward Covid-19 Infectious Disease
}

\author{
Mi-Jeung Ahn \\ Department of Nursing, Andong National University, Andong-si, Gyeongsangbuk-do, Korea
}

Corresponding author: Mi-Jeung Ahn, Department of Nursing, Andong National University, 1375, Gyeongdong-ro, Andongsi, Gyeongsangbuk-do 36729, Korea

Tel.: +82548206715

Fax: +82548206730

Email: mjahn@korea.ac.kr

Received August 13, 2021

Revised September 3, 2021

Accepted September 17, 2021

Published September 30, 2021

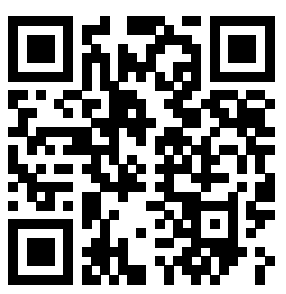

\begin{abstract}
Purpose: This study assessed the knowledge, attitude, and preventive practice of college students majoring in cosmetology toward covid-19 and the factors responsible for influencing affecting prevention practices. Methods: Data were analyzed using the Statistical Package for the Social Science (SPSS) software. Descriptive statistics (frequency and proportion), Scheffé's test for analyzing a group of and stepwise multiple regression were used for analyses. Results: College students majoring in cosmetology had deep knowledge of Covid-19. Covid-19 prevention practices were found to be affected by attitudes, knowledge, and gender. Conclusion: This study, identified factors influencing cosmetology college students' Covid-19 prevention practices. Future studies, must analyze larger samples.
\end{abstract}

Keywords: Knowledge, Attitude, Prevention practice, Covid-19, Cosmetology student

\section{Introduction}

신종전염병은 20 세기 후반 에볼라 바이러스, 광우병, 조류독감등 을 경험하면서 인류의 관심의 대상이 되어 왔다. 메르스(Middle East Respiratory, MERS), 사스(Severe Acute Respiratory Syndrome, $\mathrm{SARS}$ )와 같은 코로나 바이러스의 변형인 Covid-19(Coronavirus disease 19)는 2019년 12월 중국 우한에서 처음 보고되었고, 2020 년 2월 20일 세계보건기구(WHO)에서 Covid-19로 명칭을 변경하였 다. 이러한 Covid-19로 인한 우리의 일상이 사회적 거리 두기 등으 로 제한 되며 위축되고 있는 상황이다. 학교도 휴교령과 온라인을 통 한 비대면 수업의 반복이 최근 까지도 이어지고 있다.

우리나라의 코로나 환자가 본격적으로 확산이 시작된 2020년 6 월에서 8월 사이의 감염자 연령별 통계는 20 대 연령층인 대학생이 나 사회 초년생 인구가 4,277 명으로 10 대( 1,134 명)보다는 3 배, 30 대(2,476명), 40대(2,664명)는 약 2배정도로 많았다(Kim et al., 2021a). 20대는 활동력이 왕성한 시기이므로 타인에게 전염병을 전
파하거나 전염될 가능성이 매우 크며, 사회적 활동에 참여가 많으므 로 사회적 거리두기에 대한 인식이나 실천이 다른 연령층에 비해 낮 은 것으로 확인되었다(Atchison et al., 2020). 20대 젊은 연령층 중 대학생은 활동량이 많아 Covid-19에 더 많이 노출될 가능성이 높으 며(Kim et al., 2021a), 성인 초기인 대학생은 질환에 대한 관심이 낮고 건강에 대한 지각과 건강증진 행위에 대해서도 소홀할 가능성 이 높다.

Covid-19의 무증상 감염자는 Covid-19 감염된 시점부터 완치 까지 별다른 증상이 발현되지 않는 감염자를 말한다. 이러한 무증상 감염자는 본인이 감염된 사실을 모르기 때문에 타인에게 전파할 가 능성이 크고 유증상 감염자에 비해 더욱 더 위험하다. 중요한 사실은 무증상 감염자가 유증상 감염자와 유사한 바이러스 전파력을 가진다 는 점이다. Covid-19에 감염된 환자 중 무증상자의 비율을 종단적 으로 연구한 논문에 의하면 전체 감염자의 약 40-45\%로 나타났고, 14 일 이상의 기간 동안 바이러스를 감염 시킬 수 있는 것으로 나타났 다(Daniel \& Eric, 2020). 또한 젊은 연령층의 경우 특별한 증상이 없 
는 무증상감염일 확률이 다른 연령과 노령인구에 비해 높다(Kim et al., 2021a).

지식, 태도, 실천에 대한 연구(Knowledge, Attitude, Practice Model, KAP-model)는 스스로의 생활양식에서 오는 위험요인에 관 하여 얼마나 알고 있는지 각 개인의 조절에 따라 위험요인의 변화가 질병발생이나 조기 사망의 위험을 변화 시킬 수 있는 태도를 갖고 있 는 지와 위험요소를 감소시킬 수 있는 지 건강행태를 조사하는 것 으로서 보건교육 이전에 대상집단을 진단할 수 있고 위험집단을 구 분 할 수 있는 방법이다. 따라서 본 연구를 통한 뷰티전공 대학생의 Covid-19에 대한 지식, 태도, 예방실천을 확인하고 보건교육과 중재 의 기초자료를 마련하고자 수행하였다.

Covid-19는 뷰티 산업에도 영향을 미치고 있으며, 트랜드의 변 화를 인식하고 이를 극복하기 위한 새로운 대응 전략을 수립(Park \& $\mathrm{Kim}, 2021)$ 하고 있는 실정이다. Covid-19의 대유행 상황은 뷰티 교 육에도 큰 영향을 미치고 있으며, 미래의 뷰티 산업의 전문가들로 일 할 뷰티전공 학생에게 신종 감염병에 대한 지식과 태도 예방실천 행 위는 매우 중요하다고 생각된다. 뷰티전공 학생들이 현재 경험하고 있는 신종감염병인 Covid-19에 대한 정확하지 않은 지식과 부정적 인 태도와 낮은 감염예방 실천행위는 감염병에 대한 막연한 두려움과 고객에 대한 부정적인 인식과 태도가 유발될 수 있어 고객을 기피할 우려가 있다고 예상된다. 이에 뷰티학과 학생들은 졸업 후 뷰티 산업 전문가로 직간접적으로 감염병에 노출된 상황에서 고객을 응대하고 서비스를 제공하고 전문가로 현장에서 고객에게 보건교육을 하는 주 체가 되어야 하기 때문에(Ahn \& Park, 2019) Covid-19에 대한 지 식, 태도, 예방실천 행위에 대한 정확한 인식은 반드시 필요하다.

현재까지 이루어진 국내 선행연구는 대학생을 대상으로 Covid-19 에 대한 지식, 위험인식, 주관적 규범, 지각된 행동에 대한 연구(Kim et al., 2021a), Covid-19 지식, 교육요구도 및 예방행위에 대한 연 구(Kim et al., 2021b), 간호대학생을 대상으로 Covid-19 지식, 불 안, 예방행위수행정도에 대한 연구(Hwang \& Lee, 2020)가 대부분 이며 Covid-19에 대한 지식, 태도, 예방실천에 대한 연구가 미미한 실정이며, 또한 뷰티전공 대학생을 대상으로 한 연구는 매우 드문 실 정이다.

이에 본 연구에서는 Covid-19의 대유행 상황에서 뷰티전공 대학 생의 Covid-19에 대한 지식, 태도, 예방실천 행위를 파악하고자 하 였다. 본 연구를 근거로 뷰티전공 대학생을 대상으로 Covid-19와 신 종전염감염병 예방실천 행동을 적극적으로 이행 할 수 있는 프로그램 혹은 교육프로그램 개발 시 기초자료로 활용될 수 있을 것으로 사료 된다.

본 연구의 목적은 뷰티전공 대학생의 Covid-19에 대한 지식, 태 도, 예방실천을 파악하고자 함이며 구체적인 목적은 다음과 같다.

1) 뷰티전공 대학생의 Covid-19에 대한 지식, 태도, 예방실천 행위 를 확인한다.

2) 뷰티전공 대학생의 일반적 특성에 따른 Covid-19에 대한 지식,
태도, 예방실천 행위를 확인한다.

3) 뷰티전공 대학생의 Covid-19에 대한 지식, 태도, 예방실천 행위 의 상관관계를 확인한다.

4) 뷰티전공 대학생의 Covid-19에 대한 예방실천 행위에 영향을 미 치는 요인을 확인한다.

\section{Methods}

\section{1. 연구 설계}

본 연구의 목적은 뷰티전공 대학생의 Covid-19에 대한 지식, 태 도, 예방실천 행위를 확인하고 이들의 상관관계와 예방실천행위에 영향을 미치는 요인을 확인하고자 한 서술적 조사연구이다.

\section{2. 연구 수집 방법 및 대상}

본 연구는 경기도 $\mathrm{Y}$ 시에 위치한 $\mathrm{Y}$ 대학교의 뷰티를 전공하는 대학 생을 대상으로 2021년 5월 3일에서 5월 21일 까지 진행되었다. 설 문조사는 Covid-19의 유행상황이므로 사회적 거리를 유지하기 위 하여 온라인 설문 참여 방법으로 조사하였다. 연구대상자의 수는 $G^{*}$ power program 3.19를 이용하여 산정 시, 상관관계 양측 검정에 서 유의수준 0.05 , 보통 효과크기 0.30 을 기준으로 0.95 의 검정력을 위해 최소 138 명 이상이 요구 되었다. 설문에 대한 응답은 166 명이 응답하였고 이중 충실하지 않은 12 명의 응답을 탈락시키고 최종 154 명을 선정하여 분석하였다.

\section{3. 연구 도구}

1) 연구도구의 번역 및 타당도와 신뢰도 검증

Covid-19에 대한 지식, 태도, 예방실천 행동에 대한 측정도구는 Provenzano et al. (2020)이 대학생을 대상으로 개발한 도구를 사용 하였으며 타당도를 위하여 번역전문가가 한국어로 번역한 후, 성인 간호학 전공 교수 1 인과, 역학전공 교수 1 인, 뷰티전공 교수 1 인이 원 도구와의 일치도 및 문항의 적절성을 평가 논의하여 선정하였다.

번안된 도구의 신뢰도는 지식측정 문항 신뢰도는 Cronbach's $\alpha$ 0.81 이었고, 태도 측정 문항 신뢰도는 Cronbach's $\alpha 0.88$ 이었고, 예 방실천행동 측정 문항 신뢰도는 Cronbach's $\alpha$ 0.84이었다.

본 연구에서는 문항의 타당도와 신뢰도를 검증하고 지식 15 문항, 태도 7 문항, 예방실천 행위 8 문항으로 구성된 측정도구를 사용하였 다.

\section{2) Covid-19에 대한 지식}

Covid-19에 대한 지식에 대한 문항은 15 문항으로 Covid-19의 정 의와 감염경로, 병인과 증상에 대한 지식정도를 측정하도록 구성되 어 있다. 각 문항에 '정답'은 1 점을 부여하고, '오답'과 '잘 모르겠다'는 0점을 부여한 후 100점 만점으로 환산하여 점수를 산출하였고 총점 
의 범위는 0-100점이며 점수가 클수록 Covid-19에 대한 지식 정도 가 높은 것을 의미한다. 본 연구에서의 신뢰도는 Cronbach's $\alpha 0.81$ 이었다.

\section{3) Covid-19에 대한 태도}

Covid-19에 대한 태도에 대한 문항은 7문항으로 Covid-19 통제 에 대한 태도, Covid-19 감염자에 대한 태도, Covid-19와 관련된 정 보 공유에 대한 태도, 환자 접촉 시 태도에 대한 태도에 대해 측정하 도록 구성되어 있다. 각 문항에 따라 '부정적 태도' 0 점, '중립적 태도' 1점, '긍정적 태도' 2점을 부여하였다. 총점의 범위는 0-14점이고, 점수가 높을 수록 Covid-19를 극복할 수 있다는 태도가 긍정적인 것 을 의미한다. 본 연구에서의 신뢰도는 Cronbach's $\alpha$ 0.88이었다.

\section{4) Covid-19에 대한 예방실천}

Covid-19에 대한 예방실천행동에 대한 문항은 8문항으로 문항의 내용은 손 씻기와 마스크 착용, 기침 시 행동, 사용한 휴지 처리, 감 염 의심자 소지품 만진 후 행동, 주변인에 대한 교육 실천 등으로 구 성되어 예방실천행동을 측정하도록 구성되어 있다. 각 문항에 따라 전혀 실천하지 않는다' 0점에서 '매우 잘 실천한다' 4점의 Likert 척도 로 측정되고 총점의 범위는 0-32점이며, 점수가 높을수록 Covid-19 에 대한 예방실천행동이 높은 것을 의미 한다. 본 연구에서의 신뢰도 는 Cronbach's $\alpha 0.84$ 였다.

\section{4. 분석 방법}

수집된 자료는 SPSS/WIN(Version 25, SPSS Inc., Chicago, IL, $\mathrm{USA}$ )프로그램을 사용하여 분석하였고, 자료분석 방법은 다음과 같
다.

1) 대상자의 특성, Covid-19에 대한 지식, 태도, 예방실천은 기술통 계로 분석하였다.

2) 측정도구의 신뢰도는 KR20, Cronbach's $\alpha$ coefficients로 산출하 였다.

3) 대상자의 특성에 따른 Covid-19에 대한 지식, 태도, 예방실천의 차이는 independent $t$-test, ANOVA, 사후검정은 Scheffe' test로 분 석하였다.

4) Covid-19에 대한 지식, 태도, 예방실천의 상관관계는 Pearson correlation coefficients로 분석하였다.

5) Covid-19관련 예방실천에 영향을 미치는 요인은 Stepwise multiple regression으로 분석하였다.

\section{5. 윤리적 고려}

본 연구는 연구윤리 지침에 따라 연구대상자에게 연구의 목적과 설문지 작성 요령에 대한 자세한 설명을 한 후 자발적 의사에 따라 연 구에 참여하겠다는 동의서를 받고 진행하였다. 연구 대상자는 연구 에 참여하기로 동의 한 후에도 언제든지 연구참여를 거부하거나 중단 할 수 있음을 설명하고, 이에 대한 어떠한 불이익도 발생하지 않음 을 설명하였다. 수집된 정보는 연구 이외의 목적으로 활용되지 않으 며, 부호와 된 설문의 응답에 대해 철저히 보호되고, 연구 종료 후 완 전히 폐기 된 다는 점에 대해 자세히 설명하였다. 설문 조사는 약 15 $\min$ 정도 소요되었으며 설문에 참여한 대상자에게 소정의 답례품을 제공하였다.

Table 1. Knowledge, attitude, and preventive practices for Covid-19 according to the characteristics of the participant ( $\mathrm{N}=154)$

\begin{tabular}{|c|c|c|c|c|c|c|c|c|}
\hline \multirow{2}{*}{ Variables } & \multirow{2}{*}{ Categories } & \multirow{2}{*}{$\mathrm{N}(\%)$} & \multicolumn{2}{|c|}{ Covid-19 related Knowledge } & \multicolumn{2}{|c|}{ Attitude toward Covid-19 } & \multicolumn{2}{|c|}{ Preventive practice Covid-19 } \\
\hline & & & $\mathrm{M} \pm \mathrm{SD}$ & $t$ or $F(p)$ & $\mathrm{M} \pm \mathrm{SD}$ & $t$ or $F(p)$ & $\mathrm{M} \pm \mathrm{SD}$ & $t \operatorname{or} F(p)$ \\
\hline \multirow{2}{*}{ Gender } & Male & $4(2.6)$ & $83.66 \pm 7.02$ & \multirow{2}{*}{$1.63(0.106)$} & $9.32 \pm 1.02$ & \multirow{2}{*}{$4.19(<0.001)$} & $28.20 \pm 1.59$ & \multirow{2}{*}{$3.86(0.002)$} \\
\hline & Female & $150(97.4)$ & $85.22 \pm 5.43$ & & $10.55 \pm 1.22$ & & $29.87 \pm 1.22$ & \\
\hline \multirow{4}{*}{ Grade } & Freshman & $38(24.7)$ & $84.08 \pm 9.21$ & \multirow{4}{*}{$0.35(0.654)$} & $10.49 \pm 1.34$ & \multirow{4}{*}{$0.27(0.647)$} & $29.48 \pm 1.42$ & \multirow{4}{*}{$3.43(0.016)$} \\
\hline & Sophmore & $42(27.3)$ & $84.52 \pm 7.37$ & & $10.33 \pm 1.29$ & & $29.24 \pm 1.65$ & \\
\hline & Junior & $38(24.7)$ & $84.73 \pm 7.42$ & & $10.43 \pm 1.23$ & & $29.52 \pm 1.40$ & \\
\hline & Senior & $36(23.3)$ & $85.69 \pm 7.23$ & & $10.44 \pm 1.07$ & & $29.97 \pm 1.32$ & \\
\hline \multirow{3}{*}{$\begin{array}{l}\text { Subjective } \\
\text { health status }\end{array}$} & Poora & $14(9.1)$ & $85.09 \pm 7.42$ & \multirow{3}{*}{$0.25(0.679)$} & $10.14 \pm 1.21$ & \multirow{3}{*}{$\begin{array}{r}5.84(<0.036) \\
\text { b,c }>a^{*}\end{array}$} & $26.65 \pm 1.51$ & \multirow{3}{*}{$\begin{array}{r}4.32(0.021) \\
b, c>a^{*}\end{array}$} \\
\hline & Averageb & $72(46.8)$ & $84.30 \pm 8.24$ & & $10.56 \pm 1.32$ & & $29.04 \pm 1.26$ & \\
\hline & Goodc & $68(44.1)$ & $84.77 \pm 7.28$ & & $10.62 \pm 1.16$ & & $29.88 \pm 1.32$ & \\
\hline \multirow{2}{*}{$\begin{array}{l}\text { Covid-19 } \\
\text { related } \\
\text { education }\end{array}$} & Yes & $73(47.4)$ & $85.78 \pm 6.35$ & \multirow{2}{*}{$1.15(0.318)$} & $10.40 \pm 1.25$ & \multirow{2}{*}{$1.15(0.096)$} & $29.54 \pm 1.75$ & \multirow{2}{*}{$1.81(0.524)$} \\
\hline & No & $81(52.6)$ & $84.54 \pm 7.23$ & & $10.31 \pm 1.21$ & & $28.36 \pm 1.63$ & \\
\hline \multirow{2}{*}{$\begin{array}{l}\text { Need for } \\
\text { Covid-19 } \\
\text { education }\end{array}$} & Need & 117 (76.0) & $85.86 \pm 7.54$ & \multirow{2}{*}{$1.07(0.285)$} & $10.52 \pm 1.32$ & \multirow{2}{*}{$2.18(0.125)$} & $29.67 \pm 1.65$ & \multirow{2}{*}{$3.22(0.326)$} \\
\hline & Needless & $37(24.0)$ & $84.67 \pm 7.27$ & & $10.32 \pm 1.02$ & & $29.51 \pm 1.65$ & \\
\hline
\end{tabular}

*Scheffé's test; M \pm SD, mean \pm standard deviation. 


\section{Results}

\section{1. 대상자의 일반적 특성}

연구 대상자는 여학생(97.4\%)로 남학생(2.6\%)보다 많았고, 학 년은 2 학년(27.3\%)로 가장 많았다. 대상자의 주관적 건강상태는 보통'이 $46.8 \%$, '좋음' $44.1 \%$, '나쁨' $9.1 \%$ 의 순으로 조사 되었다. Covid-19에 대한 교육 경험은 없다가 $52.6 \%$ 였고, Covid-19에 대 한 교육의 '필요하다'는 $77.6 \%$ 로 '필요없다'에 비해 높게 나타났다 (Table 1).

\section{2. 대상자가 지각한 Covid-19에 대한 지식, 태도, 예방실천}

연구대상자의 Covid-19에 대한 지식점수는 100점 만점에 평균 $85 \pm 6.25$ 점 이었고, Covid-19에 대한 태도 점수는 14점 만점에 평

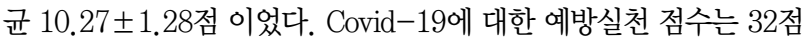

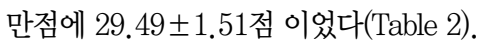

\section{3. 대상자의 특성에 따른 Covid-19에 대한 지식, 태도, 예방실천}

대상자의 특성에 따른 Covid-19에 대한 지식의 차이를 분석한 결 과 모두 유의한 차이는 없었다 $(p>0.05)$. 대상자의 특성에 따른 태도 는 성별 $(t=4.19, p<0.001)$, 주관적 건강상태 $(F=5.84, p<0.036)$ 에 따라 유의한 차이가 있었다. 즉, 여학생 집단이 남학생 집단 보다,
자신의 건강상태를 '보통이다', '좋다'로 인식한 집단이 나쁘다고 인 식한 집단보다 Covid-19에 대한 태도가 더 높게 나타났다.

대상자의 특성에 따른 Covid-19 예방실천은 성별 $(t=3.86$, $p=0.002)$, 학년 $(F=3.43, p=0.016)$, 주관적 건강상태 $(F=4.32$, $p=0.021)$ 에 따라 유의한 차이가 있었다. 즉 여학생 집단이 남학생 집단보다, 자신의 건강상태를 자신의 건강상태를 '보통이다', '좋다' 로 인식한 집단이 나쁘다고 인식한 집단보다 예방실천이 높았다. 학 년에 따른 사후 검정에서는 차이가 없었다(Table 1).

\section{4. 지식, 태도, 예방실천의 상관관계}

본 연구의 변수들의 상관관계를 분석한 결과 Covid-19관련 예방 실천은 Covid-19에 관한 지식(r=0.15, $p=0.006)$, Covid-19에 관 한 태도 $(\mathrm{r}=0.33, p<0.001)$ 과 각각 유의한 정 상관관계가 있는 것으 로 나타났다(Table 3).

\section{Covid-19 예방실천에 영향을 미치는 요인}

연구 대상자의 Covid-19 예방실천에 영향을 미치는 요인을 파악 하기 위하여 기술통계에서 일반적 특성 중 유의한 차이를 보인 성 별, 학년, 주관적 건강상태와 상관분석에서 유의한 상관관계를 보인 Covid-19에 대한 지식과 태도를 다중회귀분석식에 투입한 후 단계 적 회귀분석을 실시 하였다. 이중 명목척도인 성별, 학년, 주관적 건

Table 2. Participants's perceived knowledge of Covid-19, attitudes, and prevention practices

\begin{tabular}{lccc}
\hline Variables & $\mathrm{M} \pm \mathrm{SD}$ & Min Max & Range \\
Covid-19 related Knowledge & $85.02 \pm 6.25$ & $43.27-98.20$ & $1-15$ \\
Attitude toward Covid-19 & $10.27 \pm 1.28$ & $2.00-12.00$ & $0-14$ \\
Preventive practice for Covid-19 & $29.48 \pm 1.51$ & $2.00-30.00$ & $0-32$ \\
\hline
\end{tabular}

$\mathrm{M} \pm \mathrm{SD}$, mean \pm standard deviation.

Table 3. Correlation between knowledge, attitude and preventive practice

\begin{tabular}{lcc}
\hline Variables & Covid-19 related knowledge & Attitude toward Covid-19 \\
\cline { 2 - 3 } Covid-19 related Knowledge & $\mathrm{R}(p)$ & $\mathrm{R}(p)$ \\
Attitude toward Covid-19 & 1 & 1 \\
Preventive practice for Covid-19 & $0.06(0.897)$ & $0.33(<0.001)$ \\
\hline
\end{tabular}

Table 4. Factor influencing preventive practice of Covid-19

$(\mathrm{N}=\mathbf{1 5 4})$

\begin{tabular}{lccccc}
\hline Variables & $\mathrm{B}$ & $\mathrm{SE}$ & $\beta$ & $t$ & $p$ \\
(Constant) & 2.02 & 0.86 & & 2.39 & 0.18 \\
Attitude toward Covid-19 & 0.36 & 0.05 & 0.30 & 6.70 & $<0.001$ \\
Covid-19 related knowledge & 0.24 & 0.06 & 0.18 & 3.67 & $<.001$ \\
Gender(female) & 0.43 & 0.12 & 0.16 & 3.21 & 0.003 \\
& \multicolumn{2}{c}{$\mathrm{R}^{2}=0.215$, Adj $\mathrm{R}^{2}=0.20, F=23.46, p<0.001$} & & \\
\hline
\end{tabular}

Stepwise method variables included Covid-19-related knowledge, attitude toward Covid-19, gender=dummy variable (male=1), grade=dummy variable $($ Senior $=1)$, subjective health status=dummy variable $($ poor $=1)$.

Adj=adjusted; SE=standard error. 
강상태는 가변수(dummy variables)로 전환하였다. 독립변수간의 상관계수는 0.80 미만으로 나타나 서로 독립적임이 확인되어 모든 변수를 분석에 투입하였다.

선형회귀분석의 기본가정검정은 다중공선성 진다, 잔차, 특이값 으로 진단하였다. 분석결과 Durbin-Waston 통계량이 1.28 로 자기 상관이 없었으며, 공차 한계치가 0.89-1.00으로 0.1 이상 나타났 고, 분산팽창지수(VIF)도 1.01-1.24로 10을 넘지 않아 문제가 없었 다. 따라서 회귀분석 결과는 타당한 것으로 확인되었다.

Covid-19 예방실천에 영향을 미치는 요인을 분석한 결과, 가 장 주요한 예측요인은 Covid-19에 대한 태도 $(\beta=0.30, p<0.001)$, Covid-19에 대한 지식( $\beta=0.18, p<0.001)$, 성별(여학생) $(\beta=0.15$, $p=0.003)$ 의 순으로 나타났다. 이 모형의 설명력을 나타내는 수정된 결정계수(Adj $R^{2}$ )는 0.20 으로 설명력은 $20 \%$ 였으며, 회귀모형을 통 계적으로 유의한 것으로 나타났다 $(F=23.46, p<0.001)$ (Table 4).

\section{Discussion}

본 연구는 뷰티 전공 학생들의 따른 Covid-19에 대한 지식, 태 도, 예방실천을 확인하고 예방실천에 영향을 미치는 요인을 파 악하고자 수행하였다. 연구 결과 뷰티 전공 대학생들은 따른

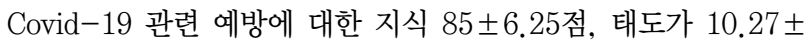
1.28 점으로 높은 수준으로 나타났다. 또한 성별, 주관적 건강상태 에 따라 Covid-19에 대한 태도에 차이가 있었고, 성별, 학년, 주관 적 건강상태에 따라 Covid-19에 대한 예방실천에 차이가 있었다. Covid-19에 대한 예방실천에 영향을 미치는 요인은 태도, 지식, 성 별(여학생)의 순으로 확인 되었다.

Covid-19가 유행한지 1년 6 개월 이상이 지난 후 진행된 이 연구 에서 뷰티 전공 대학생의 지식수준은 약 85점으로 나타났다. 이는 동일한 도구를 사용한 이태리 간호대학생에게 측정했던 점수 약 95 점(Provenzano et al., 2020) 보다는 낮지만, 일반 대학생을 대상으 로 측정한 연구((Kim et al., 2021b)의 선행연구에서 나타난 약 74 점, 보다는 높은 수준으로 나타났다. 이는 뷰티전공 대학생들의 교 육과정에 감염병과 보건학 관련된 교과목이 편성되어 있다는 점이 일반대학생에 비해 지식수준이 좀 더 높게 나타날 수 있다고 사료된 다.

본 연구에서 뷰티전공 대학생의 Covid-19에 대한 태도 점 수는 14 점 만점에 약 10 점으로 동일한 연구를 수행한 선행연구 (Provenzano et al., 2020)에서 나타난 12점 보다는 낮았다. 국내의 대학생을 대상으로 한 선행연구들 중 간호대학생들의 Covid-19 태 도 측정한 연구(Park et al., 2021) 32점 만점에 17점으로 나타난 연 구는 확인할 수 있었으나, 일반 대학생 및 뷰티전공 대학생을 대상 으로 한 연구는 확인 할 수 없어 직접 비교가 어려웠다.

뷰티전공 대학생의 Covid-19에 대한 예방실천 점수는 32
점 만점에 29점으로 나타났고, 동일한 도구를 사용한 선행연구 (Provenzano et al., 2020)에서 나타난 30점 보다는 조금 낮았다. 일반 대학생을 대상으로 측정한 선행연구(Kim et al., 2021a) 20점 만점에 8점 보다는 높았다. 이는 Covid-19에 대한 지식이 높을수록 예방 실천이 높다는 선행연구((Kim et al., 2021a; Jung \& Hong, 2020; Park et al., 2021)와 일치 하였다.

본 연구에서 뷰티전공 대학생의 Covid-19에 대한 예방실천 에 영향을 미치는 가장 주요한 예측요인은 Covid-19에 대한 태도 $(\beta=0.30, p\langle 0.001)$, Covid -19 에 대한 지식 $(\beta=0.18, p\langle 0.001)$, 성 별(여학생) ( $\beta=0.15, p=0.003)$ 의 순으로 나타났다. 뷰티전공 대학 생의 대학생의 Covid-19에 대한 예방실천에 영향을 미치는 요인을 연구한 선행연구를 확인 할 수 없어 직접적인 비교는 어려웠지만, 보건계열 대학생의 Covid-19에 대한 예방실천에 영향을 미치는 요 인을 연구한 선행연구(Kim et al., 2020)에서는 지식과 태도, 전공 (간호학)이 영향을 미치는 요인으로 나타나 본 연구와 유사한 결과 를 나타내었다.

성별(여학생)이 Covid-19에 대한 예방실천에 영향을 미치는 요 인으로 나타난 것은 뷰티학과의 여학생 비율이 압도적으로 높았 기 때문과 여성은 남성보다 질병에 대한 감수성이 높을 수 있어 Covid-19에 대한 인식의 가능성이 높다. 이것은 여학생 비율이 높 은 뷰티전공 학과에서 여학생들이 예방실천에 영향을 주는 요인이 라는 본 연구의 결과를 설명할 수 있다.

본 연구에는 몇 가지 제한 점이 있다. 첫째 특정지역의 대상자를 통해 자료를 수집하였기 때문에 일반화 하기 어렵다. 둘째, 본 연구 는 단면조사 연구이기 때문에 추후 종단 적인 연구를 제언한다. 그 리고 추후 연구에서는 표본을 확대하여 분석하는 것이 필요하다고 생각된다. 셋째, 대상자의 Covid-19에 대한 태도, 예방실천은 주관 적 건강상태에서 유의한 차이를 보였고, 이는 여학생 집단이 남학생 집단보다 자신의 주관적 상태를 '보통이다', '좋다'로 인식한 학생보 다 예방실천이 높은 결과를 나타내었으나, 본 연구에서 남학생의 비 율이 여학생의 비율보다 현저하게 낮아 결론을 일반화 하기에는 어 렵다. 따라서 추후에는 남녀의 비율을 교정하여 확대한 표본으로 분 석하는 것이 필요하다고 생각된다.

그러나 이러한 제한 점에도 불구 하고 본 연구의 강점은 뷰티전공 대학생들을 위한 신종전염병 감염예방 및 교육프로그램에 대한 기 본 정보를 제공하기 위해 사용될 수 있다. 현재 뷰티전공 대학생들 을 위한 감염예방 교육은 이론수업에서 지식전달에 중점을 두고 있 다. 본 연구에서 신종전염병 질환에 대한 지식, 태도 예방 실천에 대 한 확인은 신종전염병 질환의 예방실천 행동을 향상시키기 위한 감 염예방 교육프로그램에 대한 통찰력을 제공할 수 있다. 


\section{Conclusion}

본 연구는 뷰티전공 대학생들의 Covid-19에 대한 지식, 태도, 예 방실천을 파악하고 예방실천에 영향을 미치는 주요한 요인을 파악 하고자 하였다. 연구결과 뷰티전공 대학생들은 주관적 건강인식에 있어 '보통이다'라는 생각이 가장 높았고, Covid-19에 대한 교육의 필요성이 높게 나타났다. 뷰티전공 대학생들은 Covid-19에 대한 높 은 지식을 가지고 있었다. Covid-19와 관련된 예방실천은 지식과 태도와 상관성이 높았고, Covid-19와 관련된 예방실천에 영향을 미 치는 주요 요인은 태도와 지식, 성별로 확인 되었다. 따라서 뷰티전 공 대학생의 감염병 예방교육 과정에서 전염병에 대한 정확한 정보 를 제공하고 지식과 태도를 강화 하는 것이 예방실천을 하는데 도움 이 될 수 있다고 사료된다.

\section{Author's contribution}

MJA reviewed literature, performed questionnaires, analyzed the data and wrote the manuscript.

\section{Author details}

Mi-Jeung Ahn(Lecturer), Department of Nursing, Andong National University, 1375, Gyeongdong-ro, Andong-si, Gyeongsangbuk-do 36729, Korea,

\section{References}

Ahn MJ, Park SJ. Mediation effect of self-efficacy on the relationship between knowledge of and compliance with hand washing in cosmetology students. Asian Journal of Beauty and Cosmetology, 17: 277-286, 2019.

Atchison CJ, Bowman L, Vrinten C, Redd R, Pristera P, Eaton JW, Ward H. Perceptions and behavioural responses of the general public during the COVID-19 pandemic: a crosssectional survey of UK Adults. British Medical Journal Open, 11: e043577, 2021.

Daniel PO. Eric JT. Prevalence of asymptomatic SARS-CoV-2 Infection. Annals of Internal Medicine, 174: 286-287, 2020.
Hwang SJ, Lee MI. Perceived knowledge, anxiety and compliance with preventive behavior performance on COVID-19 by nursing college students. Journal of Digital Convergence, 18: 459-468, 2020.

Jung AR, Hong EJ. A study on anxiety, knowledge, infection possibility, preventive possibility and preventive behavior level of COVID-19 in general public. Journal of Convergence for Information Technology, 10: 87-98, 2020.

Kim YB, Yoon TH, Sohn AR. Effects of COVID-19 knowledge, risk perception, subjective norms, and perceived behavioral control on preventive action intentions and preventive action practices in college students. Korean Journal of Health Education and Promotion, 38: 25-36, 2021a.

Kim JH, Yun JS, Park JY. A study of the knowledge and educational needs of college students about coronavirus disease-2019 and preventive behavior adopted against it. Journal of The Korean Society of Integrative Medicine, 9: 109-121, 2021b.

Kim HR, Choi EY, Park SY, Kim EA. Factors influencing preventive behavior against coronavirus disease 2019 (COVID-19) among medically inclined college students. Journal of Korean Academy of Fundamentals of Nursing. 27: 428-437, 2020.

Park SJ, Han JE, Kwak KH. The influence of nursing students' knowledge, attitudes and infection prevention behaviors for COVID-19 upon the nursing intention for patients with the emerging infectious diseases. The Journal of Korean Nursing Research, 5: 13-23, 2021.

Park YM, Kim HY. A study on changes in women's make-up interest and use patterns before and after the outbreak of COVID-19. Asian Journal of Beauty and Cosmetology, 19: 129-138, 2021.

Provenzano S, Santangelo OE, Armetta F, Pesco G, Allegro A, Lampasona M, Terranova A, D’Anna G, Firenze A. COVID-19 infection: comparing the knowledge, attitude and practices in a sample of nursing students. Acta Biomed for Health Professions, 91: e2020001, 2020. 


\section{국문초록}

\section{뷰티전공 대학생의 Covid-19에 대한 지식, 태도, 예방실천}

안미정

국립안동대학교 간호학과, 경상북도 안동시, 한국

목적: 본 연구는 뷰티전공 대학생의 Covid-19에 대한 지식, 태도, 예방실천을 확인하고 예방실천에 영향을 미치는 요인을 확인하 고자 하였다. 방법: 분석은 SPSS/WIN프로그램을 사용하였다. Covid-19에 대한 지식, 태도, 예방실천은 기술통계를 사용하였고 Covid-19 예방실천에 대한 분석은 Stepwise multiple regression을 사용하였다. 결과: 뷰티전공 대학생들은 Covid-19에 대한 높은 지식을 가지고 있었다. Covid-19와 관련된 예방실천은 태도와 지식, 성별에 영향을 받는 것으로 확인 되었다. 결론: 본 연구를 통해 뷰티 전공 대학생의 Covid-19 예방실천에 영향을 미치는 요인을 확인하였다. 추후 연구에서는 표본을 확대하여 분석하는 것이 필 요하다고 생각된다.

핵심어: 지식, 태도, 예방실천, 코로나 19 , 미용학생

\section{참고문헌}

김용범, 윤태훈, 손애리. 한국대학생의 코로나 19 에 대한 지식, 위험인식, 주관적 규범, 지각된 행동 통제력이 코로나 19에 대한 예방행동 의도와 실천에 미치는 영향. 보건건강증진학회지, 38: 25-36, 2021a.

김진희, 윤정숙, 박재영. 코로나바이러스 감염증-19(Covid-19)에 대한 대학생의 지식, 교육요구도 및 예방행위 수행도. 대한통합의학회지, 9: 109-121, 2021b.

김혜란, 최은영, 박신영, 김은아. 보건의료계열 학생의 코로나바이러스 감염증-19 예방행동에 영향을 미치는 요인. 기본 간호학회지, 27: 428-437, 2020.

황순정, 이명인. 간호대학생이 지각한 Covid-19의 지식, 불안이 예방행위 수행정도에 미치는 영향. 디지털융복합연구, 18: 459-468, 2020.

박선정, 한지은, 곽근혜, 간호대학생의 코로나-19에 대한 지식, 태도, 감염예방행위가 신종감염병 환자 간호의도에 미치 는 영향. 한국간호연구학회지, 5: 13-23, 2021.

박윤미, 김휘율. 코로나 19 (Covid-19) 발생 이전 이후의 여성 화장 관심도 및 화장품 사용실태 변화 분석. 아시안뷰티화장 품학술지, 19: 129-138, 2021.

안미정, 박선주. 미용계열 대학생의 손씻기 지식과 수행의 관계에서 자기효능감의 매개효과. 아시안뷰티화장품학술지, 17: 277-286, 2019.

정애리, 홍은주. 코로나 19에 대한 불안, 지식, 감염가능성, 감염예방가능성, 감염예방행위 수행에 관한 연구. 융합정보논 문지, 10: 87-98, 2020. 


\section{中文摘要}

\section{美容专业学生对新冠病毒-19感染性疾病的知识、态度和预防实践}

安美貞

安东大学护理学科, 庆尚北道安东市, 韩国

目的：探讨美容专业大学生对新冠病毒-19的知识、态度和预防措施，以及影响预防措施的因素。方法: 使用社会 科学统计软件包（SPSS）对数据进行分析。采用描述性统计（频率和比例）、Scheffés检验和逐步多元回归进 行分析。结果: 美容专业大学生对新冠病毒19有较深的认识。发现新冠病毒-19预防措施受态度、知识和性别的 影响。结论: 本研究确定了影响美容专业大学生新冠病毒-19预防行为的因素。今后的研究认为需要扩大标本进 行分析。

关键词: 知识，态度，预防实践，新冠病毒-19，美容专业学生 